Revista Iberoamericana. Vol. LXIV, Núms. 184-185, Julio-Diciembre 1998; 457-469

\title{
MODERNIDAD Y RETÓRICA: EL MOTIVO DE LA COPA EN DOS TEXTOS MARTIANOS
}

POR

Miguel GoMes

The University of Connecticut-Storrs

\section{EL MODERNISMO O LA ORIGINALIDAD IMITADORA}

Sabida es la importancia que tuvo en el modernismo la codificación de imágenes que llevó a la creación de un lenguaje colectivo. El dios Pan, cisnes, hadas, centauros, colores alegóricos: Gwen Kirkpatrick en un estudio reciente, ya imprescindible, ha hablado de stock images (10); si, por nuestra parte, empleásemos una expresión sacada de la retórica antigua -y tal elección, espero, se justificará a lo largo de estas páginas-, podríamos asegurar que nos hallamos ante una verdadera tópica, es decir, un conjunto de topoi koinoi que surgen de distintas fuentes y delatan diversidad de preferencias: el neoclasicismo rococó, el romanticismo huguiano (38), el parnasismo, el simbolismo, el decadentismo, el prerrafaelismo e, incluso, el naturalismo. El sistema no deja, sin embargo, de resultar paradójico, al menos desde el punto de vista de lectores posteriores: ¿cómo ser "modernista", partidario de lo nuevo, y al mismo tiempo aceptar lugares comunes? ¿Cómo ser moderno sin ser absolutamente original?

Para poner en perspectiva el contrasentido previo, convendría que nos remitiéramos a "Los colores del estandarte" (1896), ensayo de Darío donde se alababa una literatura que siguiera el modelo del "alambique" y que, incluso a través de la mezcla, de la imitación de todos los autores queridos, llegase a la ansiada novedad moderna; pese a los préstamos, "el caso es que resulté original”, afirmaba el nicaragüense (Gullón 52). Renovación no por invención a partir de la nada, sino por reutilización de tradiciones. Los topoi que hemos inventariado a grandes rasgos eran también materiales que habían de entrar en la nueva substancia. En el fondo, el peligro de su pronta fosilización de un modernista a otro no debía inquietar a los adeptos al movimiento: la modernidad para éstos consistía en la sabia convivencia de lo que era el último grito de la moda con lo antiguo. Así como entre sus tendencias verbales se cuentan por igual el neologismo y el arcaísmo, así también la actitud respecto de las imágenes hechas ya tradición no era de rechazo total, sino de reescritura y recreación.

Teniendo en cuenta el marco problemático esbozado, podrá hacérsenos mucho más significativa la exploración que este trabajo se propone: la de ciertos tópicos frecuentes en el modernismo rara vez analizados por la crítica - la cual, en cambio, ha explotado hasta la saciedad otros. Específicamente, me gustaría referirme a lugares comunes que se organizan en torno a las imágenes, íntimamente relacionadas, de la sed, el vino y las copas. 
Su aparición es frecuente y susceptible de análisis que reafirmen afinidades, así como contrastes, entre distintos escritores. Nuestro punto de partida será José Martí, no sólo por su carácter de fundador y paradigma, sino porque el conjunto de su escritura resulta un modelo perfecto de red imaginal, metáfora aplicable también, en una dimensión interautorial e intertextual, a la totalidad del modernismo. En nuestro examen privilegiaremos por cuestiones de espacio dos textos, "Amor de ciudad grande" y el "Prólogo" al Poema del Niágara, que por su naturaleza compendiadora nos servirán de puente a la obra de autores que se inscriben en campos semióticos "abiertos" por el cubano.

\section{MARTI: EL TOPOS COMO PRINCIPIO UNIFICADOR}

En 1882 compuso José Martí uno de los poemas que a la larga resultaría ser de los más admirados del modernismo: "Amor de ciudad grande", perteneciente a Versos libres. La pieza tiene una historia curiosa pues, a pesar de contarse entre las mejores de su autor, sólo fue publicada póstumamente (1913) y su influencia en la poesía de otros modernistas, por tanto, siempre será debatible. Difícilmente podría averiguarse si Martí llegó a leer el manuscrito a sus amigos o si lo hizo circular; no obstante, el poema enlaza tan magistralmente varias de las obsesiones imaginales de la época que deberíamos examinarlo con atención.

Su estructura, comparable en ciertos puntos a la de una sonata clásica en tres o cuatro movimientos, aquí cuatro estrofas - no ha de extrañarnos el subtexto musical en el siglo del simbolismo-, se abre con una introducción a la que sigue una sintética presentación de los motivos que después se desarrollarán a profundidad:

De gorja y rapidez son los tiempos.

Corre cual luz la voz; en alta aguja, Cual nave despeñada en sirte horrenda,

Húndese el rayo, y en la ligera barca

El hombre, como alado, el aire hiende.

¡Así el amor, sin pompa ni misterio

Muere, apenas nacido, de saciado!

¡Jaula es la villa de palomas muertas

Y ávidos cazadores! ¡Si los pechos

Se rompen de los hombres, y las carnes

Rotas por tierra ruedan, no han de verse

Dentro más que frutillas estrujadas! (vs. 1-12)

Los cinco primeros versos son esenciales para sentar el tono y definir el marco donde se inscribirán los restantes. La comunión de fondo y forma usualmente exigida por Martí queda expresada de inmediato en la persistencia del hipérbaton en un poema que no lo requiere por razones de rima: la rapidez de los tiempos se ratifica en un verso introductorio que comienza por el final. La prolongación de la irregularidad sintáctica en las oraciones siguientes no hace sino corroborar que el universo que se nos esboza padece un mal: confusión, desorden - “mundo al revés" (Curtius I, 143-9). ¿ ¿Qué es, si no, ese caer del

\footnotetext{
' Prueba del interés modernista en este topos es "Agencia ...", pieza que Darío incluyó en El canto errante.
} 
cielo a la tierra (el rayo) y ese ascenso al cielo de lo terrestre (el hombre alado)? ¿No es la caída de Ícaro un castigo por un pecado de soberbia contra los dioses, la aspiración de un humano a ser lo que no es, entidad celeste, divina? El "temor", el "espanto" de que hablará la conclusión del poema de Martí equivale a la actitud reverencial ante lo sagrado que el mundo moderno ha perdido y que el hablante poético clama para sanar al universo de su demente inversión de valores. Nótese que ha incluido en ese mundo al revés una "voz" que, de tan ligera, va a la misma velocidad de la luz: la suya, precavida, ha de ser, entonces, contraria - la voz del santo temor, la del que a la "gorja" opone el "dolor", también mencionado en los últimos versos. ${ }^{2}$

Luego de tal marco, nos topamos con una enumeración de los tres motivos que ocuparán las secciones posteriores del texto: el amor como sed o bebida; la caza como metáfora de la vida moderna; $\mathrm{y}$, finalmente, el alma como fruta dañada por la modernidad viciosa.

La segunda estrofa retomará la última de esas imágenes ampliando lo que ya se nos había indicado en la primera: la relación entre un cuerpo humano roto, fragmentado, y una ruina espiritual paralela. El mal de los tiempos empieza por la autovejación material y culmina en la anímica:

¡No son los cuerpos ya sino desechos,

$\mathrm{Y}$ fosas, $\mathrm{y}$ jirones! ¡Y las almas

No son como en el árbol fruta rica! ... (vs. 36-8)

En la tercera estrofa el tema de la caza, presentado en la primera, se retomará y llevará a sus últimas consecuencias. Si al principio se hablaba de "palomas muertas" y "ávidos cazadores", ahora se aclarará alegóricamente el significado de la comparación:

¡La edad es ésta de los labios secos!

[...] Como liebre

Azorada, el espíritu se esconde,

Trémulo huyendo del cazador que ríe ... (vs. 43-8)

La polaridad verdugo-víctima corresponde a la que rige a todo el poema: la de ligereza y miedo, o, mejor dicho, temeridad y temor. El temblor de la presa equivale aquí al "espanto" reverente y sagrado del hablante que aparecerá en los últimos versos del texto, mientras que la risa atribuida al cazador es un eco indudable de la "gorja" sacrílega atribuida a los tiempos.

${ }^{2}$ Debido a la cercanía de la palabra "gorja" ('garganta') y de la frase "de gorja”, Roberto González Echevarría sugiere que en "Amor de ciudad grande" se plasman las dificultades de la voz poética por articular su canto (166). La frase, con todo, podría entenderse también siguiendo otra acepción, respaldada por el español clásico, las indudables lecturas auriseculares martianas y la supervivencia de tales giros idiomáticos en el habla americana. "Gorja" solía significar "broma" o como lo explica el Diccionario de autoridades: "chanza, alegría, regocijo, bulla, fiesta y así se dice estar o no estar de gorja". En el romance "Érase una tarde ..." de Quevedo leemos, por ejemplo, "estaban contando / con risa y de gorja / los ardides suyos"... Por lo que se apreciará en el análisis que desarrollaremos a continuación, tal sentido es más que plausible en el poema que analizamos. 
El primer motivo expuesto en la estrofa inicial de “Amor de ciudad grande" se plasmará en una serie coherente de imágenes que resultará la más persistente a lo largo del poema, pues reaparece en las demás estrofas y las vincula: la del amor que muere "apenas nacido, de saciado". El verbo saciar indica en español, sobre todo, satisfacción de sed o hambre. El resto del poema retomará la tropología inaugural combinándola con el símbolo de la "copa" o el "vaso", y sus contenidos, "vino", "jugo", lo que, por otra parte, se amalgama a la perfección con la línea imaginal de la "fruta": nótese que las "frutillas" de la primera estrofa han sido "estrujadas" y en la tercera estrofa también se ha hecho referencia a una vida "estrujada en agraz", es decir, antes de madurar. El origen del topos, por supuesto, no era reciente - no podía escapársele a Martí, entre otras, la "sed" crística-; no obstante, me atrevería a asegurar que la novedad de "Amor de ciudad grande" radica en la conversión de dicho cliché en una original respuesta a poemas decimónicos previos con los que un autor convencido de su vocación cívica, arraigada en un sentido moral profundo, no podía estar de acuerdo hasta el punto de rendirles pasivo tributo. Pienso, desde luego, en algunas composiciones que Baudelaire agrupó bajo la rúbrica "Le Vin" en Les Fleurs du mal, en las cuales el satanismo y la sensualidad morbosa adquieren enorme intensidad: " $L$ 'Ame du vin", "Le Vin des chiffoniers", "Le Vin de l'assassin", "Le Vin du solitaire" y "Le Vin des amants". ${ }^{3}$ Particularmente en este último soneto encontraremos abundantes elementos que coinciden con el poema de Martí y podrían justificar que percibiésemos una relación intertextual estrecha; se alude a un vino sobre el que ascenderán al cielo los amantes, "ángeles" (deux anges que torture/Une implacable calenture), "balanceándose blandamente sobre el ala / de un inteligente torbellino / en un delirio paralelo" (Mollement balancés sur l'aile / Du tourbillon intelligent, / Dans un délire parallèle). Si leemos con atención el poema martiano, comprobaremos que no sólo la "fiebre", ya anunciada en el verso 50, es idéntica a la de Baudelaire, sino que la entronización que efectúa éste del delirio halla resistencia:

Se ama de pie, en las calles, entre el polvo

De los salones y las plazas; muere

La flor que nace [...].

[...] Pues ¿quién tiene

Tiempo de ser hidalgo? [...].

[...] Si se tiene sed, ise alarga el brazo

$\mathrm{Y}$ a la copa que pasa se la apura!

Luego, jla copa turbia al polvo rueda,

Y el hábil catador - manchado el pecho

De una sangre invisible - sigue alegre,

Coronado de mirtos, su camino! (vs. 13-35)

¡Me espanta la ciudad! ¡Toda está llena de copas por vaciar, o huecas copas! ¡Tengo miedo, ay de mí, de que este vino Tósigo sea, y en mis venas luego

\footnotetext{
${ }^{3}$ Menciono estos poemas sin olvidar "Sed non satiata" y otros dispuestos en distintas secciones del libro baudelairiano.
} 
Cual duende vengador los dientes clave!

$¡$ Tengo sed - mas de un vino que en la tierra

No se sabe beber! ¡No he padecido

Bastante aún, para romper el muro

Que me aparta, oh dolor, de mi vinedo!

¡Tomad vosotros, catadores ruines

De vinillos humanos, esos vasos

Donde el jugo de lirio a grandes sorbos

Sin compasión y sin temor se bebe!

¡Tomad! ¡Yo soy honrado y tengo miedo! (vs. 52-65)

Versos morales, que no abandonan ni un segundo la visión condenadora del mundo al revés, percibido ahora en el "jugo de lirio", calambur que asocia la bebida maldita con el delirio del universo caótico en que el deseo se sacia. Desarrollando nexos típicamente baudelairianos - no restringidos a "Le Vin des amants"-, la polisemia de la serie vinosangre-tósigo-jugo, además de contar ya con indudables resonancias cristianas, se complica en la segunda estrofa de "Amor de ciudad grande" con alusiones al acto sexual: la "virgen trémula", como en la tercera estrofa el espíritu-liebre "trémulo", ha sido catada-cazada por un catador-cazador que tiene "sangre invisible" sobre su pecho. La "flor", más que destruida, ha sido arrebatada y mirtos triunfales coronan al culpable. Préstese atención a que éste "sigue alegre su camino": el cazador de la estrofa siguiente, como sabemos, "ríe" ambos ejemplifican los tiempos "de gorja". La "honra" con que concluye el poema, desde luego, es atributo de la hidalguía que no se rebaja al poder adquisitivo del "rico cazador" e insiste en el poder transcendente del vino que "en la tierra no se sabe beber", o, lo que es lo mismo, en el respeto por lo sagrado que condena toda gorja.

Mucho admiró el autor cubano al francés, como lo demuestra en diversos ensayos (Vol. I-II, 908, 934), pero ese sentimiento jamás se tradujo en calco, sino en remisiones canceladoras. Martí es un ejemplo de cómo el modernismo, incluso habitando los mismos lugares de la poesía francesa, los hizo suyos de manera creadora, a través del remozamiento y la depuración. Después de todo, no sólo condenó Martí en repetidas oportunidades la decadencia de costumbres provocada por ciertos gustos europeos, sino que discurrió sobre las graves consecuencias de la adopción acrítica de lo que no pertenecía por naturaleza a "nuestra América" (Schulman 33-7).

Todo lo anterior, sin embargo, no basta para agotar la riqueza de la imaginería de "Amor de ciudad grande". Hemos de detenernos aún en una de las ramificaciones del topos de la sed que cobra poco a poco autonomía en la composición: la de la "copa" o el "vaso".

Aunque la primera estrofa no mencione ninguna copa, una metáfora de Martí sustentada por un extraño desplazamiento semántico nos dará un adelanto de la elaboración imaginal posterior. Téngase presente que se habla de "carnes rotas" que "por tierra ruedan" y en cuyo interior hay "frutillas estrujadas": la comparación cuerpo-copa no resulta obvia, pero se aclarará de inmediato cuando en la estrofa segunda se compare a la "dama gentil" con "áureo vaso" o cuando leamos que "la copa turbia al polvo rueda". Uno de los dos movimientos con que se inaugura el poema, el de la caída de lo celeste —el rayo-, se repetirá en ese rodar por los suelos - y, sin duda, en el amor de pie, "entre el polvo", de la segunda estrofa. No es coincidencia que el poema concluya con la reminiscencia de un vino 
que no pertenece a lo terrestre: esa oposición mantiene la tensión generalizada en la pieza sin resolverla dialécticamente, pues no estamos ante un discurso situado más allá del bien y del mal, sino uno que anhela el hallazgo de un centro moral, lo que supone la fe en la pureza de un término sobre su contrario en un universo organizado en dicotomías. A fin de cuentas, sólo un autor moralista podía haber sacrificado su propia vida en la lucha por sus creencias.

Entre otros, "Copa con alas", que también figura en Versos libres, es susceptible de leerse como cotexto de "Amor de ciudad grande": el sentimiento en ascenso del hablante se relaciona con la sed ultraterrenal del hombre temeroso. Por su parte, "Tórtola blanca", del Ismaelillo, podría considerarse la matriz imaginal que "Amor de ciudad grande" después desarrollará. Preferiría, no obstante, que ahora nos detuviésemos en otras páginas publicadas en 1882, justamente célebres por contener las meditaciones martianas más fascinantes acerca de la poesía: el "Prólogo" al Poema del Niágara de Juan Antonio Pérez Bonalde. Este ensayo es la obra más cercana a la composición que hemos estudiado y prueba que la unidad tópica de su escritura era mucho más esencial para Martí que las señales genéricas: en esto, su obra es precursora y claro modelo de los procedimientos modernistas -recuérdese, para no ir muy lejos, que el Lunario sentimental de Leopoldo Lugones se organizará como volumen de la misma manera: una gama de textos heterogéneos desde el punto de vista tipológico (poemas, cuentos, piezas teatrales) reunidos con el solo objetivo de variar un lugar común recibido de la tradición, la luna.

La cercanía entre el "Prólogo" y "Amor de ciudad grande" podría empezar a probarse desde el principio del ensayo, que, por recurrir a la clásica tópica del exordio de epitafios y túmulos — “Pasajero, ¡detente!"” — y a la anáfora — “¡Ruines tiempos ...!”, repiten con insistencia el segundo y el tercer párrafo--, crea una expectativa poemática en el lector, quien, desde ese momento, exigirá que la argumentación también cante: la misma hibridez genérica que cultivarían una y otra vez los modernistas. "Ruines tiempos": no he citado en vano la frase del "Prólogo"; como sucedía en "Amor de ciudad grande", la disquisición en torno a la modernidad está signada aquí por las operaciones antitéticas del mundo al revés:

[...] aparece en la Naturaleza contradictorio todo lo que es lógico; por lo que viene a suceder que esta época [...] es para los poetas [...], por la confusión que el cambio de estados, fe y gobiernos acarrea, época de tumulto y de dolores [...] (Obra literaria 206).

Y esta es la época en que las colinas se están encimando a las montañas; en que las cumbres se van deshaciendo en llanuras, época ya cercana de la otra en que todas las llanuras serán cumbres [...] (Obra literaria 209).

La guerra, antes fuente de gloria, cae en desuso, y lo que pareció grandeza comienza a ser crimen [...]. Dios anda confuso [...] (Obra literaria 209-210).

De la misma manera, los tiempos de los que hablará la prosa son de rapidez y tienen "alas", no las idealistas de otros escritos martianos, sino las ambiguas del torbellino y el vértigo: "El periódico desflora las ideas grandiosas. Las ideas no hacen familia en la mente, como antes, ni casa, ni larga vida. Nacen a caballo, montadas en relámpago, con alas ..." (Obra literaria 208). Hay ahora también "alados versos" que no son más que vehículos de hipocresía y superficialidad (Obra literaria 206). Sólo el poeta que dome semejantes pegasos y se atreva a grandes hazañas, como en eras anteriores, podrá contrarrestar los 
efectos de la precipitación. Eso se logrará cuando volvamos a escuchar los ritmos de la Naturaleza, con mayúscula. En ese instante, el ensayista retomará la aparentemente postergada meditación sobre los logros de Pérez Bonalde, que se ha enfrentado a las cataratas gigantes, monstruosas, para caballeresca, hidalgamente - recuérdese el término empleado en "Amor de ciudad grande"- demandar algo extraviado:

En este cambio de quicio al que asistimos y en esta refacción del mundo, en que la vida nueva va, como los corceles briosos por los caminos, perseguida de canes ladradores; en este cegamiento de las fuentes y en este anublamiento de los dioses, la Naturaleza, el trabajo humano y el espíritu del hombre se abren como inexhaustos manantiales puros a los labios sedientos de los poetas: ¡vacíen de sus copas de preciosas piedras el agrio vino viejo, y pónganlas a que se llenen de rayos de sol, de ecos de faena, de perlas buenas y sencillas, sacadas de lo hondo del alma, y muevan con sus manos febriles, a los ojos de los hombres asustados, la copa sonora! (Obra literaria 210).

¡Mas, cuánto cuesta hallarse a sí mismo! [...] ¡Entre ahora el bravo, el buen lancero, el ponderoso ajustador, el caballero de la libertad humana - que es orden magna de caballería-, el que se viene derechamente por la poesía épica de nuestros tiempos; el que movió al cielo las manos generosas en tono de plegaria y las sacó de la oración a modo de ánfora sonora! (Obra literaria 210).

El grial, la copa o ánfora celestial que logrará saciar la sed del artista, sólo puede obtenerse, tal como sucedía con el amante en "Amor de ciudad grande", con una actitud respetuosa, un "tono de plegaria" a través del cual cielo y tierra podrán juntarse sin violar sacrílegamente, al modo de Ícaro, el espacio divino. Vemos así que las "alas" de la modernidad al fin podrán justificarse en el poeta religioso que rehúye, en el último párrafo del "Prólogo", la "blasfemia" de aquellos que "se arrojan a corregir la obra divina":

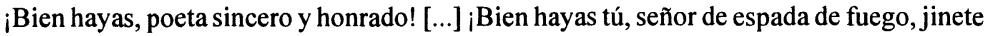
de caballo de alas, rapsoda de lira de roble, hombre que abres tu seno a la Naturaleza! Cultiva lo magno [...]. Deja a los pequeños otras pequeñeces. Muévante estos solemnes vientos [...] (Obra literaria 217).

O, en otras palabras, los "vinillos humanos" que hemos visto en "Amor de ciudad grande" no deben confundirse con la santa copa que ansía el hombre temeroso que resulta ser, según el texto en prosa, el buen poeta. Amor es poesía: combaten ambos el erial, la tierra baldía de "cegadas fuentes"; ambos luchan contra el vacío de lo que falta o se dispersa: la "ventura" ausente del poema, el "desmembramiento de la mente humana" del ensayo. Uno y otro texto se complementan para esbozar una ética y una poética paralelas: no podía ser de otra forma tratándose de Martí, para quien literatura y vida eran indisociables.

\section{LA TÓPICA: UN ESPACIO INTERTEXTUAL Y COLECTIVO}

He adelantado que a partir de "Amor de ciudad grande" y el "Prólogo" al Poema del Niágara tendríamos oportunidad de examinar otras variaciones de la tópica de la "sed metafísica" o "idealista" en el modernismo. Con ello no sugiero que sea Martí el padre de 
dicha familia de imágenes: por el contrario, creo que queda claro que su escritura se inscribe en una antigua tradición. Con todo, vale la pena reparar en un detalle: desde los años ochenta del siglo XIX ideologemas como los del vino y la copa -o el vaso- se multiplican vertiginosamente en Hispanoamérica. Aquí sí podría afirmarse que textos martianos como el "Prólogo" contribuyeron a la difusión del lugar común, debido al creciente prestigio, a veces incluso místico, que empezó a rodear al autor. Antes de Martí, Baudelaire no había ejercido todavía en español la enorme influencia que después tendría. En el cubano, los aspectos maléficos del poeta francés conviven y se contrarrestan con el optimismo sublime de la imaginería de Bécquer que, como ha demostrado Ivan Schulman, será de suma importancia en la forja de varios tropos caros a Martí. La poesía o el poeta como "vasos sagrados" o "caballos alados" son dos buenos ejemplos de ello (Schulman 72-3 y 91). Vinos infernales y paradisíacos, sensuales y metapoéticos: de la fusión o el choque de lo francés y lo español parece surgir la mayoría de las variaciones hispánicas del topos.

Gutiérrez Nájera, tradicionalmente aceptado como el otro fundador del modernismo, fue hondamente estimulado por la poesía francesa. Pero no todo en él debería explicarse, como suele hacerse, a través de ese influjo. De hecho, antes de que Darío discurriera acerca del "alambique" y teorizara sobre las mezclas imprescindibles para alcanzar la nueva originalidad posromántica, Nájera ya había hablado de "El cruzamiento en literatura" (título de un ensayo de 1894) como necesidad para quienes se impusieran la tarea de innovar. A ese mestizaje no es ajeno un pormenor que nos interesa: si bien es verdad que el afrancesamiento del mexicano lo inclinó en cierto sentido a tratar de expulsar de sus preferencias lo hispano peninsular (Schulman 96), Gutiérrez Nájera, en cambio, es de los primeros modernistas en imitar abiertamente a otro modernista, creando un espacio de familia literaria que se ensanchará a medida que crezca el movimiento. En efecto, ya Schulman ha detectado ecos notorios de Martí en Nájera, quien se sirvió "de imágenes del maestro y sintagmas anafóricos de estructura martiana" (23). Ambos escritores, por otra parte, se admiraban mutuamente y sostuvieron una amistad que ha dejado abundante huella en sus obras. Me aventuraría a sugerir aquí que a ese campo de inquietudes intertextuales pertenecen algunas de las reutilizaciones najerianas de la tópica del amor como sed, copa o bebida. Sólo que, a lo francés y a la impresión que pudieron haber causado textos martianos como el "Prólogo", se agregó una de las fuentes clásicas predilectas de Gutiérrez Nájera: Horacio. De hecho, si esto último es evidente en poemas como "Non omnis moriar", será mucho más sutil en "Para un menú" (1888), cuyo cinismo se ha comentado en varias ocasiones y cuya conexión con versos de Louis Bouilhet ha señalado Max Henríquez Ureña (73):

Las novias pasadas son copas vacías; en ellas pusimos un poco de amor; el néctar tomamos ... huyeron los días ...

¡Traed otras copas con nuevo licor! Champán son las rubias de cutis de azalia; Borgoña los labios de vivo carmín; los ojos oscuros son vino de Italia; los verdes y claros son vinos del Rhin. Las bocas de grana son húmedas fresas; 


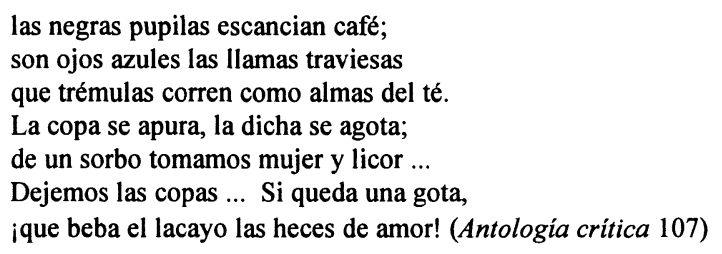

Toda la relación entre este poema y el de Bouilhet, " $A$ une femme", incluido en Festons et Astragales (1859), se reduce, como indica el mismo Henríquez Ureña, al calco del verso final (S'il reste encor du vin, les lasquais le boiront!). El comienzo de la composición, que sentará un tono melancólico para compensar la frivolidad de la enumeración central, en cambio, consiste en una aleación del motivo de la copa del mal amor, tal como se presenta en Martí, y una entrevisión de lo efímero de la existencia en la que no se observa arrepentimiento, sino gozoso hedonismo - nota original, resultado de la velada alusión al carpe diem.

Quizá también heredero martiano es el célebre Ars de José Asunción Silva, cuya primera estrofa vuelve a retratar el oficio como sacramento o búsqueda del grial: "El verso es vaso santo; poned en él tan sólo / un pensamiento puro, / en cuyo fondo bullan hirvientes las imágenes / como burbujas de oro de un viejo vino oscuro". Pero otros modernistas, más atraídos por el satanismo, preferirán retomar los aspectos sórdidos de la tópica, siguiendo de cerca a Baudelaire y a los decadentistas. El hondureño Froilán Turcios, por ejemplo, en el cuento "Pareja exótica" - publicado originalmente en Prosas nuevas (1914) e incluido en Cuentos del amor y de la muerte (1930)_, pondrá al narrador a beber "una copa de añejo porto sangriento" mientras contempla y describe las maniobras de unos desconocidos sadomasoquistas. En Turcios, como se comprenderá con facilidad, el lugar común se especializa en la fascinación por el vampirismo, frecuente en todo buen lector de Les Fleurs du mal. Hemos de llegar a principios de siglo XX para encontrar una variación realmente emancipada de lo francés en las imágenes de la copa y el vino. Los responsables serán Darío y Delmira Agustini.

El primero de ellos ya había evidenciado un influjo muy probable del "Prólogo" al Poema del Niágara en un poema juvenil fechado en 1884: "El poeta a las Musas" (de Epístolas y poemas). De hecho, en esa meditación acerca de la poesía se sitúa el oficio, precisamente, en la circunstancia angustiosa del "espíritu moderno", al que la voz poética no sabe si ensalzar o no, puesto que se caracteriza, tal como en el ensayo martiano, por la decadencia y la fragmentación del progreso: "Hoy el rayo de Júpiter Olímpico / es esclavo de Franklin y de Edison; / ya nada queda del flamante tirso, / y el ruin Champagne sucedió al Falerno". Al igual que en el "Prólogo", se advierte asimismo que la modernidad parece tener una esencia blasfema contra la que ha de luchar el poeta, en contacto aún con lo sagrado: "Todo acabó. Decidme, sacras Musas, ¿cómo cantar en este aciago tiempo / en que hasta los humanos orgullosos / pretenden arrojar a Dios del cielo?".

En Cantos de vida y esperanza (1907) el Darío ya maduro dará un paso más allá. Sabemos, por la semblanza de Martí incluida en Los raros, que admiraba particularmente la pieza XLV de Versos sencillos; aquélla donde el hablante, abrazado a la estatua de un 
héroe, exclamaba: "iOh, mármol / Dicen que beben tus hijos / Su propia sangre en las copas / Venenosas de sus dueños!". Fuesen cuales fuesen las versiones del topos que conociera, lo cierto es que Darío logra elevarlo a un plano ni satánico ni moralista, sino amoral, pues la carne, el placer, el mal, las "pequeñeces" anteriores a las que aludía Martí se tornan expresión de lo "magno" y la materia se transforma en lugar de comunicación con el espíritu, instrumento ya no del utilitarismo, sino del rito:

¡Carne, celeste carne de la mujer! Arcilla

—dijo Hugo-, ambrosía más bien, joh maravilla! [...]

¡roce, mordisco o beso

en ese pan divino

para el cual nuestra sangre es nuestro vino! [...]

Inútil es el grito de la legión cobarde

del interés, inútil el progreso

yankee, si te desdeña. [...]

Pues en ti existe Primavera para el triste,

labor gozosa para el fuerte,

néctar, Ánfora, dulzura amable.

¡Porque en ti existe

el placer de vivir hasta la muerte

ante la eternidad de lo probable! [...] (Darío, Antología crítica 216)

Las dicotomías martianas se superan y los clisés, sin desaparecer, adquieren una función nueva.

En Agustini, dichas imágenes también se transfigurarán, pero debido a la situación enunciativa poco frecuente entonces que suponía la presencia de un hablante femenino. Obsérvese, para no ir muy lejos, cómo la mujer, objeto pasivo de otros poetas (presa del cazador; copa que hay que apurar; licor; carne, a lo sumo), es aquí la catalogadora. El poema se titula "Mis amores" y podría pasar por una inversión — sexual y tonal— del menú de Gutiérrez Nájera:

Hoy han vuelto.

Por todos los senderos de la noche han venido a llorar en mi lecho.

¡Fueron tantos, son tantos! [...]

Ellos me dieron sed de todas esas bocas [...]

De todas esas bocas que florecen en mi lecho: vasos rojos o pálidos de miel o de amargura, con lises de armonía o rosas de silencio de todos esos vasos donde bebí la vida, de todos esos vasos donde la muerte bebo [...] El jardín de sus bocas venenoso, embriagante, en donde respiraba sus almas y sus cuerpos [...], ha cercado mi lecho [...] (Agustini, Antología crítica 451) 
Abundante es el recurso de Agustini al vino, a la sangre y al vaso - “de mi cuerpo", dice en otra oportunidad su simbolista Leda de rigor. ${ }^{4}$ Los cálices vacios (1913) se titula, de hecho, uno de los poemarios de la escritora: esa vacuidad física y existencial a la vez emergía de una voz marginal teñida ya de la violencia imaginativa del expresionismo sin haber eliminado aún el decadentismo decimonónico. El propósito denunciador de que Martí había dotado al topos decenios antes se preserva en el libro de Agustini, aunque adaptado a una circunstancia personal diferente.

\section{Posibles CONClusiones}

Lejos estamos de haber agotado los cuestionamientos que una poética densa como la del modernismo suscita. Lo que hemos intentado hacer, eso sí, es destacar una de las maneras que nos propone de visualizar la idea de la literatura. Sensatas palabras de Octavio Paz en Los hijos del limo han sugerido que, por la oposición modernista al racionalismo positivista, el movimiento podría considerarse como el "verdadero romanticismo" que no tuvo en su debido momento el mundo hispánico (128ss). Aunque hay mucho de cierto en lo anterior, no debe perderse de vista una inexactitud que impide llevar la tesis hasta sus últimas consecuencias: la literatura que nos propone el modernismo es radicalmente distinta de la del mejor romanticismo. ¿A qué me refiero? Una de las premisas románticas fundamentales fue la creación absoluta desde el interior del individuo. El romanticismo fue una revolución honda en todos los países, incluso en los hispánicos, porque convirtió en mala palabra el concepto de "imitación", mantenido honorablemente desde la Grecia clásica hasta el siglo XVIII. Hasta el más mediocre de los románticos de lengua española empezó a ruborizarse ante la sola idea de no ser original - no importa que, a fin de cuentas, imitara a algún maestro francés o a un compatriota: la operación se hizo velada. El romanticismo trajo un cambio mental; así como la imitatio dejó de ser bien vista, así como la noción de tradición literaria comenzó a perder prestigio, también el arte retórica pasó a formar parte de las categorías despreciables, pues se fundamentaba en la creencia de que las letras eran un fenómeno colectivo y transgeneracional, un enorme edificio que todos los hombres del pasado y el presente construían siguiendo un plan común. De los ejemplos que hemos analizado en estas páginas se desprende que el modernismo tuvo una base incluso antirromántica, pues el rubor de la imitación no fue tan radical entre sus seguidores y, a la novedad absoluta, prefirió un pacto como el que menciona Darío en "Dilucidaciones": "Amador de la lectura clásica, me he nutrido de ella, mas siguiendo el paso de mis días. He comprendido la fuerza de las tradiciones en el pasado, y de las previsiones en lo futuro". O como el que perfila Rodó en el apartado LXXVI de Motivos de Proteo (1909): "La imitación es poderosa fuerza movedora de energías y aptitudes latentes mientras deja íntegra y en punto la personalidad, limitándose a excitar el natural desenvolvimiento de ella".

Lo nuevo y lo viejo, lo propio y lo prestado juntos: en eso consistió el ideal modernista de creación, que poco tiene que ver con el radicalmente antimimético que proponía un

\footnotetext{
${ }^{4}$ El vaso o ánfora "de mi cuerpo" es una variante del tópico que reaparecerá en escritoras que tuvieron en cuenta, sin duda, las ocasiones en que lo empleó Agustini. Es frecuente en Juana de Ibarbourou (“Ofrenda", Las lenguas de diamante 1919) y Alfonsina Storni ("Una pared", El dulce daño 1918).
} 
teórico romántico como Esteban Echeverría en el decenio de 1830: "El romanticismo, pues, es la poesía moderna que fiel a las leyes esenciales del arte no imita, ni copia, sino que busca sus tipos y colores, sus pensamientos y formas en sí mismo, en su religión, en el mundo que lo rodea y produce con ellos obras bellas, originales" (54).

¿No estaban conscientes los modernistas de que sus centauros, faunos, cisnes, Ledas, vampiros, copas o vinos se repetían de un autor a otro y venían de otras tierras? Por supuesto que sabían que imitaban - pero sabían, no menos, que lo hacían hasta cierto punto: el siguiente paso era la variación, el toque moderno. "Remozar" (Díaz Rodríguez 30) o "depurar" (Lugones 92), vocablos que privilegiaron, no equivalen a "inventar". Su sistema poético - aunque lanzaran equívocos insultos contra la "retórica", tal como los románticosfue retórico en un sentido perdido: no el vulgarizado en la modernidad, sino el antiguo el del ars rhetorica, cuya cosmovisión fue tajante con respecto a las posibilidades de crear desde la nada: semejante aventura era absurda. Para el escritor de la Antigüedad, la Edad Media, el Renacimiento, el Barroco, el neoclasicismo, el universo de la cultura era un inmenso depósito de asuntos preexistentes que debía visitarse para tomar de allí los materiales necesarios con los que se elaborarían discursos "personales". En palabras de E. R. Curtius, la antigua teoría inventarió "una serie de argumentos para los casos más variados, temas ideológicos a propósito para cualquier desarrollo o variación; en griego se llaman topoi koinoi y en latín loci communes" (1: 108). Tras el paréntesis romántico, los modernistas recuperan parcialmente esa imagen del universo estético. Para ellos, como para los hombres de antaño, nada nuevo había bajo el sol - al menos, nada demasiado nuevo. Por eso en este trabajo he empleado expresiones que la retórica antigua aplicaba a los elementos imaginales o ideológicos que fundaban legados y creaban lenguajes comunes: tópico, lugar común, clisé - espacios de creación, no pérdida de personalidad creadora.

\section{BiBLIOGRAFÍA}

Agustini, Delmira. Poesías completas. A. Zum Felde, ed. Buenos Aires: Losada, 1962. Baudelaire, Charles. Le Fleurs du mal. Boston: David Godine, 1982.

Curtius, Ersnt Robert. Literatura europea y Edad Media latina. 1948. M. Frenk Alatorre y A. Alatorre, tr. 2 vols. México: F.C.E., 1981.

Darío, Rubén. Los raros. 1896. Buenos Aires: Espasa-Calpe, 1953.

Poesía. E. M. Sánchez, ed. Caracas: Biblioteca Ayacucho, 1977.

Díaz Rodríguez, Manuel. Camino de perfección. 1908. Madrid/Caracas: Editorial Edime, 1968.

Echeverría, Esteban. Obras escogidas. B. Sarlo y C. Altamirano, eds. Caracas: Biblioteca Ayacucho, 1991.

González Echevarría, Roberto. "Martí y su 'Amor de ciudad grande': notas hacia la poética de Versos libres". Ivan Schulman, ed. Nuevos asedios al modernismo. Madrid: Taurus, 1987. 160-73.

Gullón, Ricardo, ed. El modernismo visto por los modernistas. Barcelona: Labor, 1980. Gutiérrez Nájera, Manuel. Poesías completas. 2 vols. Francisco González Gutiérrez, ed. México: Porrúa, 1966.

Henríquez Ureña, Max. Breve historia del modernismo. México: F.C.E., 1978. 
Jiménez, José Olivo. Antología crítica de la poesía modernista hispanoamericana. Madrid: Hiperion, 1989.

Kirkpatrick, Gwen. The Dissonant Legacy of Modernismo. Berkeley: University of California Press, 1989.

Lugones, Leopoldo. Lunario sentimental. J. Benítez, ed. Madrid: Cátedra, 1988.

Martí, José. Obra literaria. Cintio Vitier, ed. Caracas: Biblioteca Ayacucho, 1978.

Paz, Octavio. Los hijos del limo. 1974. Barcelona: Seix Barral, 1989.

Quevedo, Francisco de. Poesía original completa. José Manuel Blecua, ed. Barcelona: Planeta, 1981.

Rodó, José Enrique. Ariel / Motivos de Proteo. Á. Rama, ed. Caracas: Biblioteca Ayacucho, 1976.

Schulman, Ivan. Génesis del modernismo. México: El Colegio de México / Washington University Press, 1966.

Silva, José Asunción. Obra completa. Eduardo Camacho Guizado y Gustavo Mejía, eds. Caracas: Biblioteca Ayacucho, 1977.

Turcios, Froilán. Cuentos del amor y de la muerte. Paris: Le livre libre, 1930. 
